\author{
Бязрова М.Г. ${ }^{1,2}$, Топтыгина А.П. ${ }^{2,3}$, Митина Т.А. ${ }^{4}$, Филатов А.В. ${ }^{1,2}$ \\ ${ }^{1}$ ФГБУ «ГНЦ „Институт иммунологии“” Федерального медико-биологического агентства России, Москва, \\ Россия \\ ${ }^{2}$ ФГБОУ ВО «Московский государственный университет имени М.В. Ломоносова», Москва, Россия \\ ${ }^{3}$ ФБУН «Московский научно-исследовательский институт эпидемиологии и микробиологии имени \\ Г.Н. Габричевского» Роспотребнадзора, Москва, Россия \\ ${ }^{4}$ ГБУЗ МО «Московский областной научно-исследовательский клинический институт имени \\ М.Ф. Владимирского», Москва, Россия
}

Резюме. При вакцинации происходит стимуляция В-клеток, и в кровотоке на короткое время появляются активированные В-лимфоциты, которые относятся к плазмобластам. Плазмобласты также наблюдаются при некоторых вирусных инфекциях. Количество плазмобластов может являться показателем успешности вакцинации или диагностическим признаком продолжающейся инфекции. Как правило, плазмобласты представлены немногочисленной популяцией клеток, определение которой встречает некоторые трудности. В исследовании приняли участие 15 здоровых добровольцев, которые были однократно иммунизированы рекомбинантной вакциной против гепатита В. Для определения плазмобластов были использованы меченные антитела, ранее полученные в нашей лаборатории. Использованные реагенты показали свою применимость для подсчета плазмобластов. Было проведено сравнение различных стратегий гейтирования плазмобластов. При окрашивании лимфоцитов иммунизированных добровольцев набором антител CD19-PE, CD3/CD14/CD16-FITC, CD27-PC5.5 и CD38-PC7 наблюдался отчетливый кластер плазмобластов с фенотипом CD27++CD38 ${ }^{++}$. Bключение в панель антитела CD20-FITC приводило к увеличению доли CD $27^{++} \mathrm{CD} 38^{++}$плазмобластов среди CD19+ лимфоцитов до 60\% и более. При замене антитела CD38 на антитело CD71 также обнаруживался отчетливый кластер плазмобластов, содержавший около 5\% В-лимфоцитов. Две стратегии гейтирования плазмобластов с использованием комбинаций CD27/CD38 и CD27/CD71 мы сравнили в динамике на лимфоцитах одного вакцинированного добровольца. При использовании сочетания CD27/CD38 на 7-й день после вакцинации регистрировался острый и выраженный пик количества плазмобластов. Применение комбинации CD27/CD71 приводило к растягиванию пика на период с 7-го по 14-й день после вакцинации. Таким образом, временная динамика популяции $\mathrm{CD} 27^{+} \mathrm{CD} 71^{+}$ отличалась от появления классических плазмобластов с фенотипом CD27 ${ }^{++} \mathrm{CD} 38^{++}$. Это наталкивает на мысль, что в популяцию $\mathrm{CD} 27^{++} \mathrm{CD} 71^{+}$входят не только плазмобласты, но также и другие типы активированных В-клеток. Был получен препарат малого поверхностного антигена гепатита В, меченного фикоэритрином (HBsAg-PE), с помощью которого было определено количество антигенспецифических плазмобластов. Результаты определения антигенспецифических клеток с помощью комплекса HBsAg-PE согласовались с данными, полученными методом ELISpot. Отработанная стратегия

\author{
Адрес для переписки: \\ Филатов Александр Васильевич \\ ФГБУ «ГНЦ „Институт иммунологии“» Федерального \\ медико-биологического агентства России \\ 115522, Россия, Москва, Каширское ш., 24. \\ Tел.: 8(499) 617-77-65. \\ E-mail:avfilat@yandex.ru
}

\author{
Address for correspondence: \\ Filatov Alexander $V$. \\ National Research Center "Institute of Immunology", \\ Federal Medical-Biological Agency of Russia \\ 115522, Russian Federation, Moscow, \\ Kashirskoye Highway, 24. \\ Phone: 7 (499) 617-77-65. \\ E-mail:avfilat@yandex.ru
}

\section{For citation:}

M.G. Byazrova, A.P. Toptygina, T.A.Mitina, A.V. Filatov

"Gating strategy for plasmablast enumeration after

hepatitis B vaccination”, Medical Immunology (Russia)/

Meditsinskaya Immunologiya, 2020, Vol. 22, no. 6,

pp. 1185-1194.

doi: $10.15789 / 1563-0625-G S F-2066$

DOI: $10.15789 / 1563-0625-G S F-2066$ 
гейтирования плазмобластов в настоящее время используется нами для определения активированных B-клеток при инфекции, вызываемой вирусом SARS-CoV-2. На следующем этапе исследования эта методика будет использоваться для сортировки антигенспецифических В-лимфоцитов, что позволит провести секвенирование генов Ig и приступить к созданию новых человеческих антител против вирусных антигенов.

Ключевые слова: плазмобласты, проточная цитометрия, вакцина против гепатита B, HBsAg, антигенспецифические В-клетки, ELISpot

\title{
GATING STRATEGY FOR PLASMABLAST ENUMERATION AFTER HEPATITIS B VACCINATION
}

\author{
Byazrova M.G..$^{\text {a b }}$, Toptygina A.P. ${ }^{\text {, c c }}$, Mitina T.A. ${ }^{\text {, }}$, Filatov A.V..$^{\text {a, }}$ \\ a National Research Center "Institute of Immunology”, Federal Medical-Biological Agency of Russia, Moscow, \\ Russian Federation \\ ${ }^{b}$ Lomonosov Moscow State University, Moscow, Russian Federation \\ ${ }^{c}$ G. Gabrichevsky Research Institute for Epidemiology and Microbiology, Moscow, Russian Federation \\ ${ }^{d}$ M. Vladimirsky Moscow Regional Research and Clinical Institute, Moscow, Russian Federation
}

Abstract. B cell stimulation develops upon vaccination, thus causing occurrence of activated B cells (plasmoblasts) in bloodstream. Similar cells are also observed in some viral infections. The contents of plasmablasts may be a marker of successful vaccination, or a diagnostic feature of ongoing infection. The plasmablasts are normally represented by a small cell subpopulation which is not easy to detect.

A study was performed with 15 healthy volunteers who were subjected to a single immunization with a recombinant vaccine against hepatitis $\mathrm{B}$ virus. To identify the plasmablasts, we have used labeled antibodies prepared in our laboratory. These reagents were previously validated for counting the plasmablasts. Different gating strategies for plasmablast gating have been compared. Upon staining of lymphocytes from immunized volunteers, we observed a distinct cluster of plasmablasts with $\mathrm{CD} 27^{++} \mathrm{CD} 38^{++}$phenotype using the following antibody set: CD19-PE, CD3/CD14/CD16-FITC, CD27-PC5.5 and CD38-PC7. Inclusion of a CD20-FITC antibody into the panel caused an increase of $\mathrm{CD} 27^{++} \mathrm{CD} 38^{++}$plasmablast ratio among $\mathrm{CD} 19^{+}$lymphocytes to $>60 \%$. Upon substitution of CD38 antibody by anti-CD71, a distinct plasmablast cluster was again revealed, which contained ca. 5 per cent B cells. Two strategies for the plasmablast gating using the CD27/ CD38 and CD27/CD71 combinations were compared in dynamics with lymphocyte samples from a single vaccinated volunteer. When applying the CD27/CD38 combination, a sharp and pronounced plasmablast peak was registered on day 7 post-vaccination. With CD27/CD71 combination, the peak was extended between day 7 and day 14 following immunization. Hence, time kinetics of the $\mathrm{CD} 27^{+} \mathrm{CD} 71^{+}$population proved to be different from occurrence of classic plasmablasts with $\mathrm{CD} 27^{++} \mathrm{CD} 38^{++}$phenotype. This finding suggests that the $\mathrm{CD} 27^{++} \mathrm{CD} 71^{+}$population contains both plasmablasts and other types of activated $\mathrm{B}$ cells. A minor HBV surface antigen was prepared and labeled with phycoerythrin (HBsAg-PE), thus allowing to quantify the antigen-specific plasmablasts. The results of HBsAg-PE-based detection of antigen-specific cells were in compliance with the data obtained by ELISpot technique. At the present time, we use the original plasmablast gating technique for detection of activated B cells in SARS-CoV-2 infection. At the next step, this technique will be applied to sorting of antigen-specific B cells, thus permitting sequencing of Ig genes and design of novel human antibodies against viral antigens.

Keywords: plasmablast, flow cytometry, hepatitis B vaccination, HBsAg, antigen-specific B cells, ELISpot

Работа выполнена при поддержке РНФ (грант № 19-15-00331).

\section{Введение}

В-клетки являются важным звеном иммунитета, они играют решающую роль при многих как вирусных, так бактериальных инфекциях. Для оценки напряженности В-клеточного иммунного ответа обычно используется определение титра антител в сыворотке пациентов. Титр антител показывает силу иммунного ответа и, как правило, коррелирует с протективным иммунитетом [28]. Однако в некоторых ситуациях титр антител является малоинформативным. При больших сроках после вакцинации, даже при отсутствии значимого количества сывороточных антител, могут присутствовать В-клетки памяти, которые способны обеспечить быстрый и эффективный ответ при повторном проникновении патогена [5, 
6, 31]. С другой стороны, непосредственно после иммунизации уровень сывороточных антител в течение одной-двух недель остается довольно низким, а иногда и не определяется вовсе. Все это указывает на то, что для характеристики иммунной реакции наряду с определением антител желательно оценивать также другие параметры В-клеточного ответа.

В результате перенесенных инфекций или под действием вакцинации формируются три популяции антигенспецифических В-лимфоцитов. К ним относятся долгоживущие плазматические клетки, В-клетки памяти и плазмобласты [4, 8]. Долгоживущие плазматические клетки сохраняются в костном мозге и длительное время продолжают секретировать антитела. Из-за своей локализации долгоживущие плазматические клетки трудно доступны для определения и анализа активности. В-клетки памяти в основном сосредоточены в периферических лимфоидных органах, но могут также обнаруживаться в кровотоке. В-клетки памяти, специфичные к данному антигену, встречаются с частотой одна клетка памяти на 2500-100 000 общих В-лимфоцитов [29]. Обычно В-клетки памяти определяют в тесте ELISpot, однако для этого необходима их предварительная стимуляция in vitro.

После антигенной стимуляции появляются плазмобласты, которые секретируют антитела и несут на своей поверхности антигенспецифические рецепторы. Поскольку плазмобласты циркулируют в крови, они являются доступным объектом для определения количества антигенспецифичных В-клеток. Наибольшее количество плазмобластов наблюдается через неделю после вакцинации, после чего они начинают переходить в долгоживущие плазматические клетки или В-клетки памяти и вскоре плазмобласты совсем исчезают из кровотока.

Наиболее часто плазмобласты определяют с помощью теста ELISpot [9], однако возможна их оценка с помощью проточной цитометрии [1]. Значительная доля плазмобластов, определенная на основании поверхностного фенотипа, представлена антигенспецифическими клетками. Например, через 7 дней после вакцинации против вируса гриппа около $80 \%$ плазмобластов были позитивными в антигенспецифическом тесте ELISpot [11]. Через неделю после иммунизации добровольцев антигенами сибирской язвы в общей популяции В-лимфоцитов обнаруживалось 0,65\% клеток с фенотипом плазмобластов, более $50 \%$ из которых представляли клетки секретирующие антитела против антигенов сибирской язвы [32].

Образование плазмобластов коррелирует со способностью В-лимфоцитов экспрессировать рецептор к IL-21, признак, по которому респондеры отличаются от нереспондеров [27]. Таким образом, определение количества плазмобластов после вакцинации является хорошим предиктором последующего образования В-клеток памяти, а также появлением антител в сыворотке на 28-й день после вакцинации [13]. При острой вирусной инфекции SARS-Cov-2 происходит массивное образование плазмобластов, доля которых может достигать $30 \%$ и более от всех В-клеток [19]. Увеличенное количество плазмобластов наблюдается в течение всего заболевания, вызванного респираторно-синцитиальным вирусом человека, и определение плазмобластов может являться диагностическим признаком продолжающейся инфекции [20]. Плазмобласты также представляют интерес как источник генов для быстрого получения человеческих моноклональных антител [37].

Все эти данные указывают на важность определения плазмобластов. В настоящем исследовании были поставлены следующие задачи. Вопервых, оценить дизайн многоцветной панели моноклонов, которые ранее были получены нами против поверхностных антигенов, для определения плазмобластов. Во-вторых, на примере иммунизации вакциной против вируса гепатита В, сравнить несколько стратегий гейтирования плазмобластов.

\section{Материалы и методы}

В исследовании приняли участие 15 здоровых добровольца в возрасте от 18 до 65 лет. Все добровольцы дали информированное согласие на проведение исследования. Добровольцев однократно внутримышечно иммунизировали дрожжевой рекомбинантной вакциной против гепатита В (HBsAg) производства Комбиотех (Россия) в дозе 20 MKГ.

Через 7 дней после иммунизации венозную кровь собирали в вакуумные пробирки с напылением гепарина. Выделение и анализ лимфоцитов проводили в день взятия крови. Фракцию мононуклеарных клеток крови выделяли с помощью центрифугирования в градиенте плотности

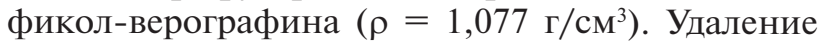
эритроцитов из образцов проводили с использованием лизирующего раствора FACS Lysis buffer (BD, США). После разрушения эритроцитов образцы однократно отмывали избытком физиологического раствора.

В работе были использованы моноклональные антитела, полученные нами ранее [18]: CD3 (клон LT3), CD16 (клон LNK16), CD19 (клон LT19), CD20 (клон LT20), CD27 (клон LT27), CD38 (клон EM5), CD71 (клон LT71), а также CD14 (клон MEM-18) производства Exbio. Подбор комбинаций антител и красителей осуществляли в соответствии с рекомендациями [24, 30]. Антитела против CD3, CD14, CD16 и CD20 метили FITC [36], антитела против CD19, CD27, CD38 и CD71 метили фикоэритрином или комплексом 
фикоэритрина с красителями Су5.5 или Су7 [7]. Клетки окрашивали смесью моноклональных антител CD3-FITC, CD14-FITC, CD16-FITC и CD20-FITC, а также CD19-PE, CD27-PE-Cy7, CD38-PE-Су5.5. Окрашивание производили в течение 30 мин при комнатной температуре, после чего клетки два раза отмывали в физиологическом растворе забуференном фосфатами. Перед измерением клеточную суспензию пропускали через ситечко с диаметром пор 40 мкм.

Конъюгат рекомбинантного HBsAg (Комбиотех) с фикоэритрином (HBsAg-PE) получали методом Click Chemistry [25]. Для этого препарат $\mathrm{HBsAg}$, содержавший смесь в равной пропорции субтипов ау и ad, активировали тетразином, а фикоэритрин - трансциклооктеном, после этого активированные белки смешивали в соотношении 1:1 и коньюгат выделяли с помощью гельфильтрации на Superdex 200. Реакцию ELISpot ставили на планшете, лунки, которого были покрыты HBsAg или посторонним белком. При постановке реакции использовали реагенты фирмы R\&D Systems (США).

Регистрацию флуоресценции проводили на проточном цитометре CytoFLEX S (Beckman Coulter, США), оснащенном двумя диодными лазерами 488 и 561 нм. Клетки сортировали с помощью прибора SH800 (Sony, США). Обработку

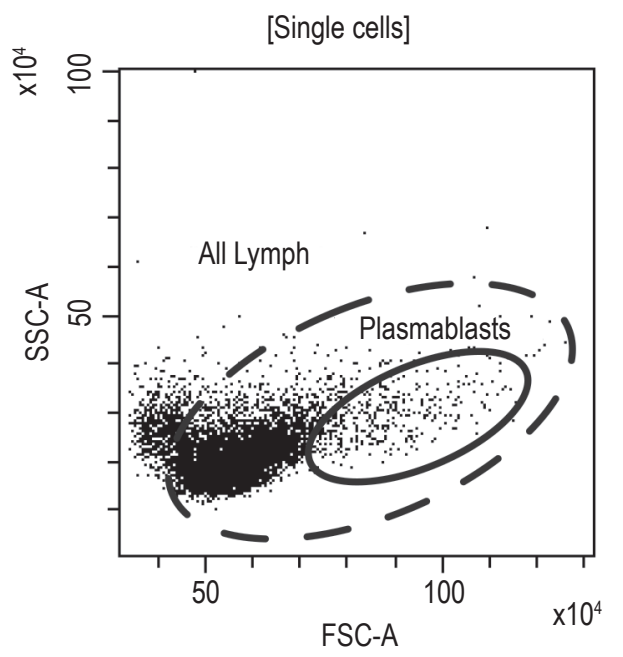
Рисунок 1. Гейтирование плазмобластов по параметрам
светорассеяния

Примечание. По оси абсцисс - малоугловое светорассеяние (FSC), по оси ординат - светорассеяние под углом $90^{\circ}$ (SSC). Область "All Lymph" использовалась для гейтирования, область "Plasmablasts" очерчивает события, полученные в результате обратного гейтирования популяции CD19+CD27++CD38++.

Figure 1. Plasmablast gating using light scattering parameters Note. Abscissa, forward scattering (FSC), ordinate, side scattering (SSC). The "All Lymph" region was used for gating, the "Plasmablasts" region outlines the events resulting from the back-gating of the CD $19^{+} \mathrm{CD} 27^{++} \mathrm{CD} 38^{++}$population. цитофлуориметрических данных проводили при помощи программы FlowJo. Для каждого из образцов анализировали не менее 10000 одиночных В-лимфоцитов. Достоверность различий оценивали с помощью критерия Манна-Уитни. Различия считали достоверными при уровне значимости $\mathrm{p}<0,05$.

\section{Результаты}

Стратегия гейтирования плазмобластов была отработана нами на лимфоцитах, полученных от добровольцев, прошедших иммунизацию вакциной против гепатита В. Как правило гейтирование лимфоцитов начинается с выбора зоны анализа на бипарамерической цитограмме в координатах малоуглового светорассеяния (FSC) и светорассеяния под углом $90^{\circ}$ (SSC) $[2,3]$. Известно, что по морфологическим параметрам плазмобласты могут отличаться от покоящихся лимфоцитов [34]. По сравнению с обычными лимфоцитами плазмобласты имеют несколько большие размеры и более высокую гранулярность. Для того чтобы при регистрации не потерять часть плазмобластов, мы выбирали более расширенную зону анализа, чем при обычной настройке на кластер лимфоцитов. Впоследствии, после нахождения плазмобластов по комбинации поверхностных маркеров, было выполнено «обратное гейтирование», которое показало, что в координатах светорассеяния популяция плазмобластов располагается несколько правей и выше кластера обычных лимфоцитов (рис. 1). Дублеты клеток исключали из рассмотрения, проводя дополнительное гейтирование в координатах малоуглового светорассеяния при измерении высоты импульса светорассеяния против его площади. Полученную популяцию обозначали на графиках как "Single cells".

Для уменьшения количества ложно позитивных событий из рассмотрения в первую очередь исключали клетки, окрашенные антителами против антигенов CD3, CD14 и CD16. Поскольку для всех этих антигенов использовался негативный критерий отбора, то для экономии каналов регистрации все три антитела использовали в форме коньюгата с одним и тем же красителем, а именно FITC.

Для определения плазмобластов мы использовали несколько подходов. Наиболее очевидным является определение плазмобластов среди $\mathrm{CD} 19^{+}$лимфоцитов. При окрашивании лимфоцитов иммунизированных добровольцев набором антител CD19-PE, CD3/CD14/CD16-FITC, CD27-PC5.5 и CD38-PC7 наблюдался отчетливый кластер $\mathrm{CD} 27^{++} \mathrm{CD} 38^{++}$клеток (рис. 2A). Другим пан-В-клеточным маркером является CD20, который дает очень яркое окрашивание В-клеток, однако он не подходит для положительного гейтирования плазмобластов. Среди 
A (A)

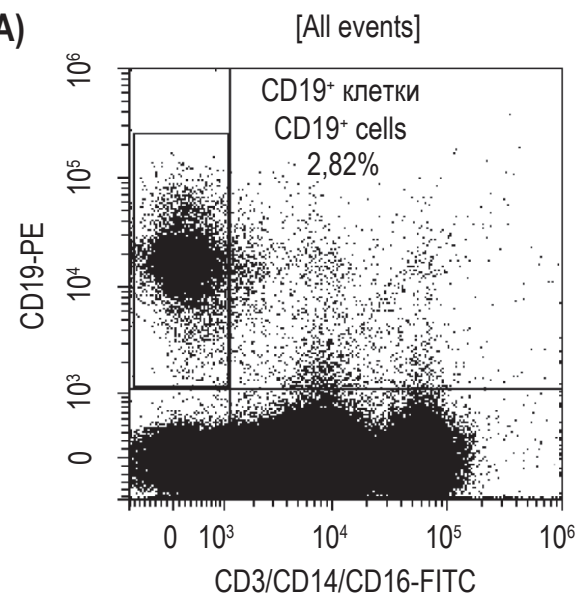

B (B)

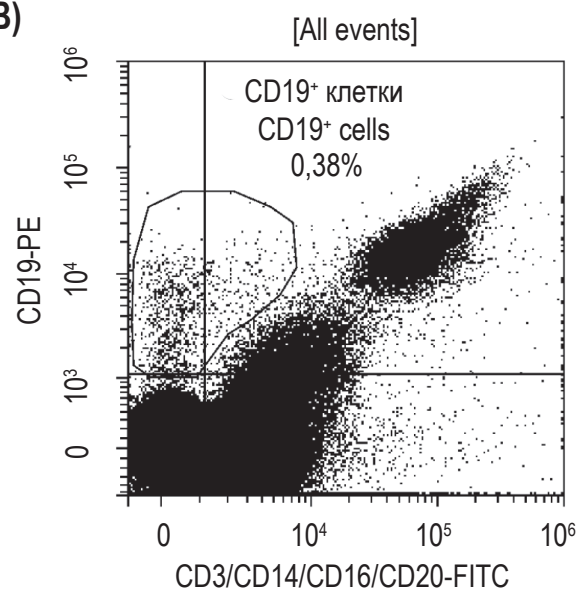

$B(C)$

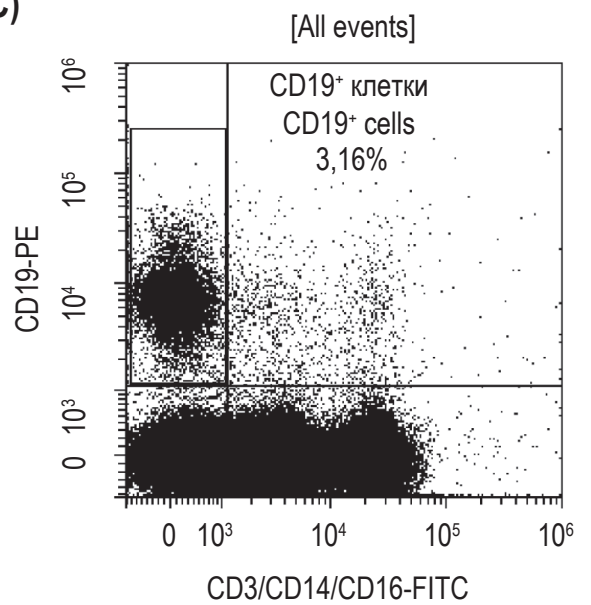

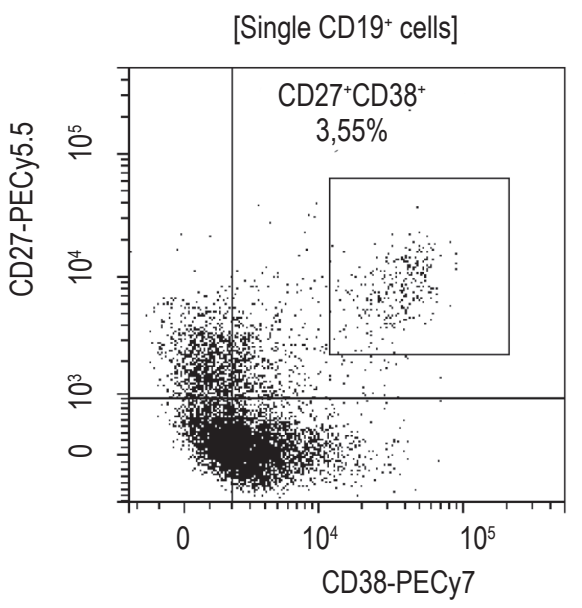
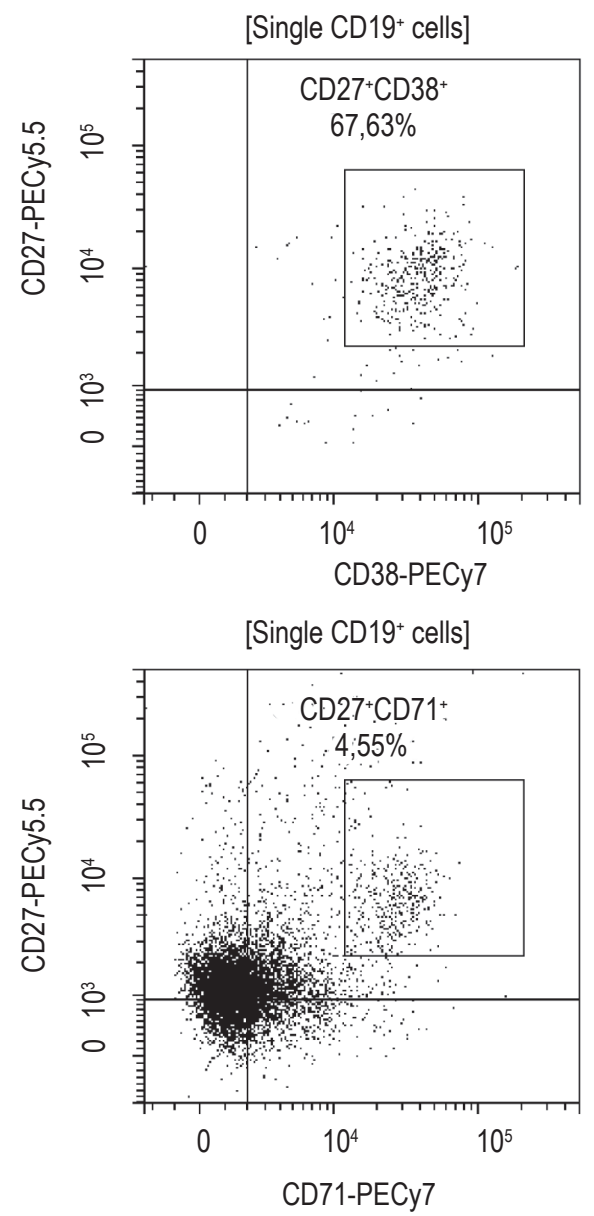

Рисунок 2. Стратегии гейтирования для определения плазмобластов

Примечание. На цитограммах слева выделение популяции В-лимфоцитов производили по положительному окрашиванию антителом CD19-PE (ось ординат) и негативному окрашиванию антителами CD3/CD14/CD16-FITC (A, B) или CD3/CD14/CD16/ CD20-FITC (Б) (ось абсцисс). Цифрами указана доля выделенных клеток по отношению ко всем лимфоцитам. На цитограммах справа выделенные В-лимфоциты дополнительно гейтировались по положительному окрашиванию антителом CD27-PECy5.5 (ось ординат) и CD38-PECy7 (A,Б) или CD71-PECy7 (B) (ось абсцисс). Цифрами указана доля выделенных клеток по отношению к выделенным одиночным CD19+ клеткам.

Figure 2. Gating strategies for the analysis of plasmablast subse

Note. Left column, the $B$ lymphocytes population were gated by positive staining with CD19-PE (ordinate axis) and negative staining with CD3/CD14/CD16-FITC (A, C) or CD3/CD14/CD16/CD20-FITC (B) (abscissa axis). The numbers indicate the proportion of selected cells in relation to all lymphocytes. Right column, the gated B lymphocytes were stained with CD27-PECy5.5 (ordinate axis) and CD38-PECy7 (A, B) or CD71-PECy7 (C) (abscissa axis). The numbers indicate the proportion of selected cells with respect to selected single CD19+ cells. 


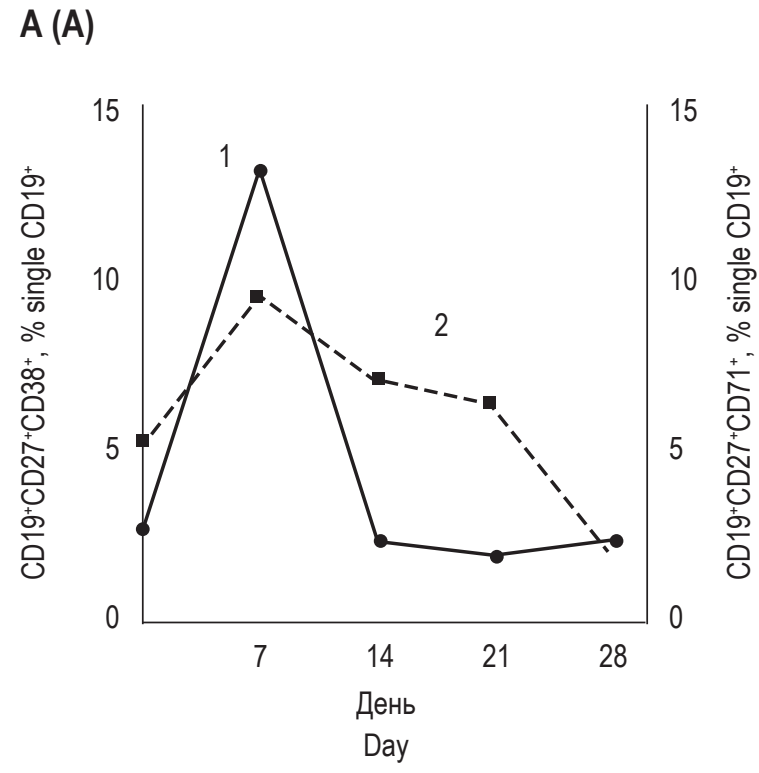

E (B)

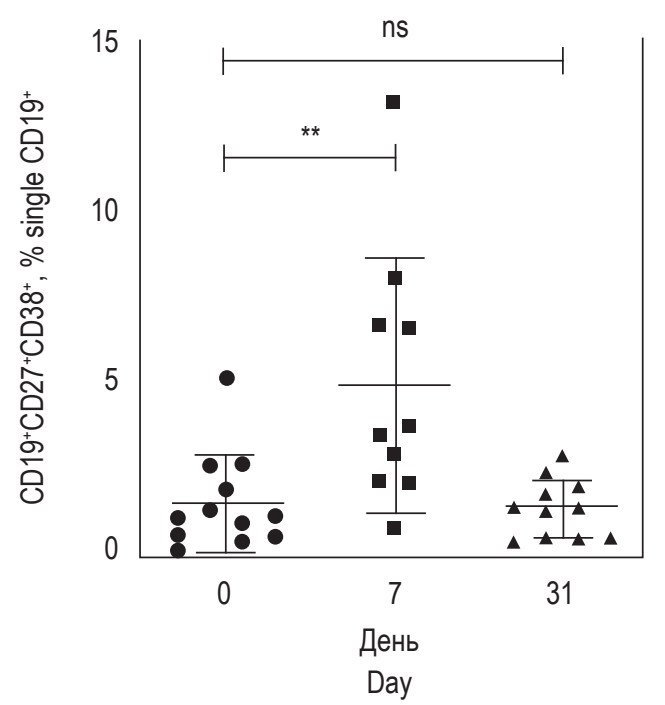

Рисунок 3. Динамика появления плазмобластов в крови добровольцев, иммунизированных вакциной против гепатита B

Примечание. По оси абсцисс - количество дней после иммунизации, по оси ординат - \% плазмобластов среди общего количества CD19+ клеток. Плазмобласты определяли при окрашивании клеток комбинацией CD27/CD38 (А и Б, ось ординат слева) или CD27/CD71 (A, ось ординат справа). ** p < 0,006; ns - разница статистически недостоверна.

Figure 3. Changes in the percentage of plasmablasts after hepatitis $B$ vaccination

Note. Abscissa, the number of days after immunization; ordinate, $\%$ of plasmablasts among the total number of $\mathrm{CD} 19^{+}$cells. Plasmablasts were determined by staining with a combination of CD27/CD38 ( $A$ and $B$, the ordinate axis is on the left) or CD27/CD71 ( $A$, the ordinate axis is on the right). ${ }^{* *}, p<0.006$; ns, the difference is not statistically significant.
$\mathrm{CD} 20^{+}$популяции количество клеток с фенотипом $\mathrm{CD}_{27} 7^{++} / \mathrm{CD} 38^{++}$было не более $0,3 \%$, что лишь незначительно превышало фоновые значения. Это хорошо согласуется с данными о том, что в процессе созревания В-клетки частично или полностью теряют CD20 [10, 23]. Отсутствие CD20 на плазмобластах дает возможность для негативного гейтирования этого типа клеток. Включение CD20 в канал негативной селекции приводило к увеличению доли $\mathrm{CD} 27^{++} \mathrm{CD} 38^{++}$ клеток среди CD19+ лимфоцитов до $60 \%$ и более. (рис. 2Б). При замене антитела CD38 на антитело CD71 также обнаруживался отчетливый кластер, содержавший около 5\% В-лимфоцитов (рис. 2В). Это предполагает, что маркер CD71 может использоваться вместо CD38.

Две стратегии гейтирования плазмобластов с использованием комбинаций CD27/CD38 и CD27/CD71 мы сравнили в динамике на лимфоцитах одного вакцинированного добровольца. При использовании сочетания CD27/CD38 на 7-й день после вакцинации регистрировался острый и выраженный пик количества плазмобластов (рис. 3А). Применение комбинации CD27/CD71 приводило к растягиванию пика на период с 7-го по 14-й день после вакцинации (рис. 3А). Дальнейшие эксперименты были выполнены при использовании комбинации CD27/ CD38. У 10 добровольцев на 7-й день после вакцинации было показано достоверное увеличение количества плазмобластов ( $<0,006)$, по сравнению с исходным уровнем $\mathrm{CD} 27^{++} \mathrm{CD} 38^{++}$клеток (рис. 4Б). Через месяц количество плазмобластов нормализовалось.

Наибольший интерес для оценки иммунного ответа представляет определение антиген специфичных плазмобластов. Антигеном вакцины Комбиотех является малый поверхностный антиген гепатита B (HBsAg), который мы коньюгировали с фикоэритрином (HBsAg-PE). При иммунизации добровольцев вакциной против гепатита В на 7-й день среди В-клеток появлялись лимфоциты, связывающие комплекс HBsAg-PE. На рисунке 4A приведены результаты, полученные для одного из доноров. Наибольшее количество антигенспецифических клеток (26\%) наблюдалось среди популяции плазмобластов CD $19+\mathrm{CD} 27^{++} \mathrm{CD} 38^{++}$(рис. 4A, левая панель). Комплекс фикоэритрина с посторонним контрольным белком Control-PE связывался не более чем с $3 \%$ плазмобластов (рис. 4А, правая панель). Примечательно, что среди наивных В-лимфоцитов $\left(\mathrm{CD} 19^{+} \mathrm{CD} 27^{-}\right)$связывание коньюгата HBsAg-PE также было на уровне фона и не превышало 1\%. Уровень $\mathrm{HBsAg}-\mathrm{PE}^{+}$клеток у иммунизированных добровольцев был достоверно выше по сравнению с контрольной группой неиммунизированных доноров $(\mathrm{p}<0,02 ; \mathrm{n}=6)$ (рис. 4Б). 
$A(A)$

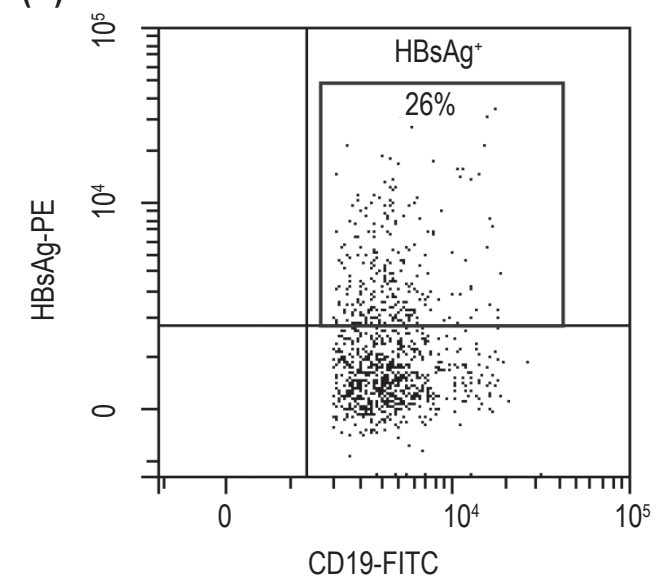

B (B)

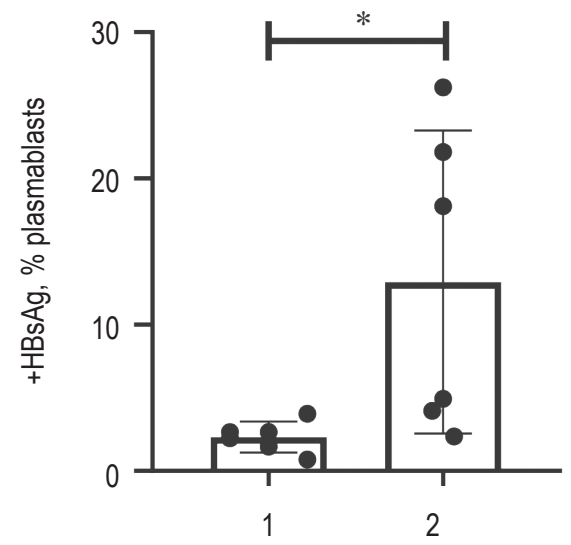

$\mathrm{CD} 27^{+} \mathrm{CD} 38^{+}$

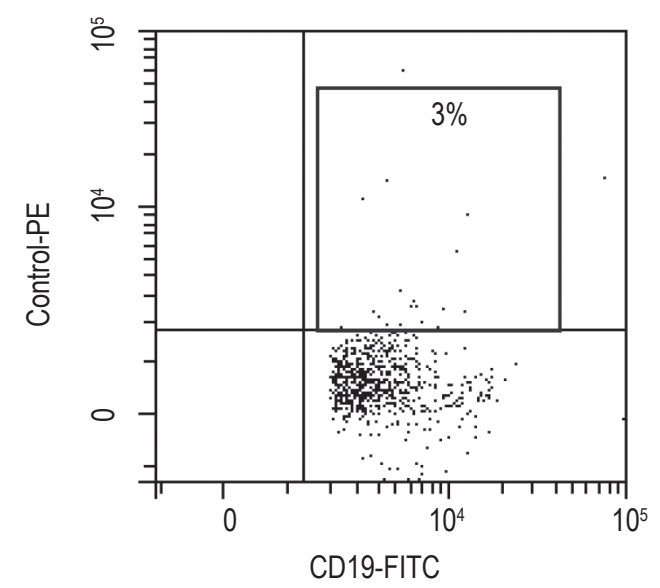

$B(C)$

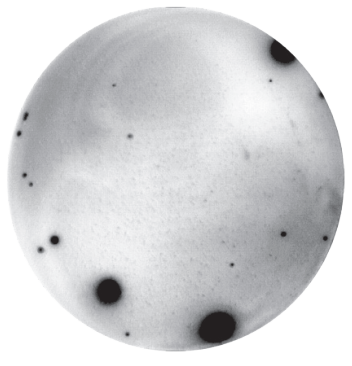

1

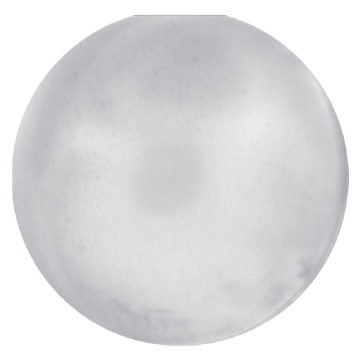

2

Рисунок 4. Выявление антигенспецифичных плазмобластов при иммунизации вакциной против гепатита В Примечание. A - цитограммы при окрашивании плазмобластов вакцинированного добровольца комплексом HBsAg-PE (слева) или комплексом фикоэритрина с посторонним контрольным белком Control-PE (справа). Б - сравнение количества HBsAg клеток у вакцинированных (1) и невакцинированных (2) добровольцев. ${ }^{*}-p<0,02, n=6$. В - определение клеток, секретирующих специфические антитела против HBSAg методом ELISpot. Слева приведена лунка, содержавшая 300 плазмобластов, справа лунка, содержавшая 300 наивных B-лимфоцитов с фенотипом CD19+CD27:

Figure 4. Identification of antigen specific plasmablasts after hepatitis $B$ vaccination

Note. A, plasmablasts of a vaccinated volunteer were stained with $\mathrm{HBsAg-PE}$ complex (left) or phycoerythrin complex with unrelated control protein Control-PE (right). B, comparison between the number of HBsAg ${ }^{+}$cells in vaccinated (1) and unvaccinated (2) volunteers. ${ }^{*}, p<0.02, n=6$. $\mathrm{C}$, determination of cells secreting HBsAg specific antibodies by ELISpot. On the left is the well containing 300 plasmablasts, on the right is a well containing 300 naive $B$ lymphocytes with the CD19+CD27- phenotype.

Для одного иммунизированного добровольца плазмобласты были отсортированы и по 300 клеток добавлены в лунки планшета для ELISpot. В лунках, покрытых HBsAg, детектировалось от 5,7 до 6,3\% антигенспецифических клеток (рис. 4В, левая панель). В контрольных лунках, содержавших по 300 наивных В-лимфоцитов (отрица- тельный контроль), антигенспецифических клеток обнаружено не было (рис. 4В, правая панель).

\section{Обсуждение}

Согласно литературным данным, пик количества плазмобластов наступает на 7-й день после иммунизации [13]. Однако даже в этот момент их количество невелико и не превышает несколько 
процентов от популяции всех В-лимфоцитов. Для надежного определения плазмобластов необходимо применять чувствительные методы детекции редких популяций клеток при максимально возможном исключении ложноположительных событий. С этой целью нами были использованы моноклональные антитела против поверхностных антигенов лимфоцитов человека ранее полученные в нашей лаборатории. Многие из этих антител прошли тестирование на Международных Воркшопах по дифференцировочным антигенам лейкоцитов человека [12]. В данной работе мы получили коньюгаты этих антител с органическими флуорофорами, флуоресцирующими белками, а также с тандемными красителями. Полученные антитела обеспечивали необходимый уровень флуоресценции антигенпозитивных клеток, а также позволяли выполнить надежную компенсацию. С использованием полученных реагентов нами была отработана стратегия гейтирования плазмобластов, возможности которой были продемонстрированы при определении плазмобластов у добровольцев, иммунизированных вакциной против гепатита В.

Наиболее часто для выделения плазмобластов используют коктейль, содержащий антитела против антигенов CD19, CD27 и CD38 [1, 11]. В дополнении к этому желательно один канал использовать для негативной селекции (dump channel), что позволяет существенно снизить количество ложно-позитивных событий. В первую очередь негативной селекции подлежат $\mathrm{CD}^{+}$, $\mathrm{CD}_{14}^{+}$и $\mathrm{CD}_{16}^{+}$клетки. Исключение $\mathrm{IgM}^{+}, \mathrm{IgD}^{+}$, $\mathrm{IgA}^{+}$, а также CD20+ клеток также улучшает выделение плазмобластов [23, 33]. В некоторых случаях для финишного гейтирования плазмобластов добавляют также антитела против CD24 [16], CD21 и CD95 [17], CD71 и Ki67 [11], CD138 [13], CD70 [21] и некоторые другие.

Плазмобласты являются активно пролиферирующими клетками, поэтому можно ожидать появление на их поверхности рецептора к трансферрину CD71. Возможность использования CD71 для определения плазмобластов ранее была продемонстрирована в работе [11]. При окрашивании CD19+ клеток комбинацией CD27/CD71 обнаруживался отчетливый кластер, содержавший около 5\% В-лимфоцитов (рис. 2В). Однако временная динамика этой популяции отличалась от появления классических плазмобластов с фенотипом CD $27^{++} \mathrm{CD} 38^{++}$. Это наталкивает на мысль, что в популяцию $\mathrm{CD} 27^{++} \mathrm{CD} 71^{+}$входят не только плазмобласты, но также и другие типы активированных В-клеток, поэтому подход, связанный с применение маркера CD71, по нашему мнению, не является оптимальным. Стратегия гейтирования плазмобластов CD19+/CD20-, CD3/CD14/CD16, CD27 ${ }^{++}$и CD38 ${ }^{++}$с использованием маркера CD20 для негативной селекции была принята нами как наиболее эффективная. Обнаруженная нами динамика появления и количество плазмобластов соответствует литературным данным, полученным при иммунизации столбнячным токсином [14], гемагглютинином вируса гриппа [15] и некоторыми другими антигенами.

Обращает на себя внимание то, что окрашивание плазмобластов вакцинированных доноров с помощью комплекса HBsAg-PE давало довольно небольшое количество антигенположительных клеток. Однако наши данные вполне соответствовали наблюдению, что при иммунизации столбнячным токсином только одна клетка из каждых 1000 плазмобластов окрашивалась меченым антигеном [22, 26]. Для одного из добровольцев было проведено сравнение количества антигенположительных клеток, определенное при окрашивании комплексом $\mathrm{HBsAg}-\mathrm{PE}$, и количества клеток, секретирующих антитела против HBsAg, определенное методом ELISpot. При отнесении к общему количеству плазмобластов эти два метода дали сопоставимые величины: 4,3 и $6,0 \%$ соответственно. Эти значения соответствуют литературным данным по определению HBsAg специфических В-клеток при вакцинации против гепатита В [35].

Отработанная стратегия гейтирования плазмобластов в настоящее время используется нами для определения активированных В-клеток при инфекции, вызываемой вирусом SARS-CoV-2. На следующем этапе исследования эта методика будет использоваться для сортировки антигенспецифических В-лимфоцитов, что позволит провести секвенирование генов Ig и приступить к созданию новых человеческих антител против вирусных антигенов.

\section{Список литературы / References}

1. Будкова А.И., Лапин С.В., Серебрякова М.К., Кудрявцев И.В., Тришина И.Н., Маслянский А.Л., Тотолян Арег А. Субпопуляционный состав В-клеток периферической крови у больных системной красной волчанкой // Медицинская иммунология, 2017. Т. 19, № 2. С. 175-184. [Budkova A.I., Lapin S.V., Serebriakova M.K., Kudryavtsev I.V., Trishina I.N., Maslyansky A.L., Totolian Areg A. B-cell subpopulations of peripheral blood in systemic lupus erythematosus. Meditsinskaya immunologiya = Medical Immunology (Russia), 2017, Vol. 19, no. 2, pp. 175-184. (In Russ.)] doi: 10.15789/1563-0625-2017-2-175-184.

2. Кудрявцев И.В., Субботовская А.И. Опыт измерения параметров иммунного статуса с использованием шестицветного цитофлуориметрического анализа // Медицинская иммунология, 2015. Т. 17 , № 1. C. 19-26. [Kudryavtsev I.V., Subbotovskaya A.I. Application of six-color flow cytometric analysis for immune profile 
monitoring. Meditsinskaya immunologiya = Medical Immunology (Russia), 2015, Vol. 17, no. 1, pp. 19-26. (In Russ.)] doi: 10.15789/1563-0625-2015-1-19-26.

3. Хайдуков С.В., Байдун Л.А., Зурочка А.В., Тотолян Арег А. Стандартизованная технология «Исследование субпопуляционного состава пимфоцитов периферической крови с применением проточных цитофлюориметров-анализаторов» // Медицинская иммунология, 2012. Т. 14, № 3. С. 255-268. [Khaydukov S., Baidun L., Zurochka A., Totolyan Areg A. Methods. Meditsinskaya immunologiya = Medical Immunology (Russia), 2012, Vol. 14, no. 3, pp. 255-268. (In Russ.)] doi: 10.15789/1563-0625-2012-3-255-268.

4. Amanna I.J., Slifka M.K. Quantitation of rare memory B cell populations by two independent and complementary approaches. J. Immunol. Methods, 2006, Vol. 317, pp. 175-185.

5. Basha S., Pichichero M.E. Poor memory B cell generation contributes to non-protective responses to DTaP vaccine antigens in otitis-prone children. Clin. Exp. Immunol., 2015, Vol. 182, no. 3, pp. 314-322.

6. Bauer T., Jilg W. Hepatitis B surface antigen-specific T and B cell memory in individuals who had lost protective antibodies after hepatitis B vaccination. Vaccine, 2006, Vol. 24, pp. 572-577.

7. Berg E.A., Fishman J.B. Labeling antibodies with Cy5-Phycoerythrin. Cold Spring Harb. Protoc., 2019, Vol. 9, 099317. https://doi.org/10.1101/pdb.prot099317.

8. Buisman A.M., de Rond C.G., Ozturk K., Ten Hulscher H.I., van Binnendijk R.S. Long-term presence of memory B-cells specific for different vaccine components. Vaccine, 2009, Vol. 28, pp. 179-186.

9. Cao Y., Gordic M., Kobold S., Lajmi N., Meyer S., Bartels K., Hildebrandt Y., Luetkens T., Ihloff A.S., Kroger N., Bokemeyer C., Atanackovic D. An optimized assay for the enumeration of antigen-specific memory B cells in different compartments of the human body. J. Immunol. Methods, 2010, Vol. 358, no. 1-2, pp. 56-65.

10. Covens K., Verbinnen B., Geukens N., Meyts I., Schuit F., Van Lommel L., Jacquemin M., Bossuyt X. Characterization of proposed human B-1 cells reveals pre-plasmablast phenotype. Blood, 2013, Vol. 121, no. 26, pp. 5176-5183.

11. Ellebedy A.H., Jackson K.J., Kissick H.T., Nakaya H.I., Davis C.W., Roskin K.M., McElroy A.K., Oshansky C.M., Elbein R., Thomas S., Lyon G.M., Spiropoulou C.F., Mehta A.K., Thomas P.G., Boyd S.D., Ahmed R. Defining antigen-specific plasmablast and memory B cell subsets in blood following viral infection and vaccination of humans. Nat. Immunol., 2016, Vol. 17, no. 10, pp. 1226-1234.

12. Engel P., Boumsell L., Balderas R., Bensussan A., Gattei V., Horejsi V., Jin B.Q., Malavasi F., Mortari F., Schwartz-Albiez R., Stockinger H., van Zelm M.C., Zola H., Clark G. CD Nomenclature 2015: human leukocyte differentiation antigen workshops as a driving force in immunology. J. Immunol., 2015, Vol. 195, no. 10, pp. 4555-4563.

13. Fink K. Origin and function of circulating plasmablasts during acute viral infections. Front. Immunol., 2012, Vol. 3, no. 78, pp. 1-5.

14. Frölich D., Giesecke C., Mei H.E., Reiter K., Daridon C., Lipsky P.E., Dörner T. Secondary immunization generates clonally related antigen-specific plasma cells and memory B cells. J. Immunol., 2010, Vol. 185, no. 5, pp. 3103-3110.

15. Galson J.D., Pollard A.J., Trück J., Kelly D.F. Studying the antibody repertoire after vaccination: practical applications. Trends Immunol., 2014, Vol. 35, no. 7, pp. 319-331.

16. Georgiou G., Ippolito G.C., Beausang J., Busse C.E., Wardemann H., Quake S.R. The promise and challenge of high-throughput sequencing of the antibody repertoire. Nat. Biotechnol., 2014, Vol. 32, no. 2, pp. 158-168.

17. Kaminski D.A., Wei C., Qian Y., Rosenberg A.F., Sanz I. Advances in human B cell phenotypic profiling. Front. Immunol., 2012, Vol. 3, 302. doi: 10.3389/fimmu.2012.00302.

18. Khvastunova A.N., Kuznetsova S.A., Al-Radi L.S., Vylegzhanina A.V., Zakirova A.O., Fedyanina O.S., Filatov A.V., Vorobjev I.A., Ataullakhanov F. Anti-CD antibody microarray for human leukocyte morphology examination allows analyzing rare cell populations and suggesting preliminary diagnosis in leukemia. Sci. Rep., 2015, Vol. 5, no. 12573, pp. 1-13.

19. Kuri-Cervantes L., Pampena M.B., Meng W., Rosenfeld A.M., Ittner C.A.G., Weisman A.R., Agyekum R., Mathew D., Amy E., Baxter A.E., Vella L., Kuthuru O., Apostolidis S., Bershaw L., Dougherty J., Greenplate A.R., Pattekar A., Kim J., Han N., Gouma S., Weirick M.E., Arevalo C.P., Bolton M.J., Goodwin E.C., Anderson E.M., Hensley S.E., Jones T.K., Mangalmurti N.S., Prak E.T.L., Wherry E.J., Meyer N.J., Betts M.R. Immunologic perturbations in severe COVID-19/SARS-CoV-2 infection. bioRxiv, 2020, 101717. doi: 10.1101/2020.05.18.101717.

20. Lee F.E., Falsey A.R., Halliley J.L., Sanz I., Walsh E.E. Circulating antibody-secreting cells during acute respiratory syncytial virus infection in adults. J. Infect. Dis., 2010, Vol. 202, no. 11, pp. 1659-1666.

21. Leggat D.J., Khaskhely N.M., Iyer A.S., Mosakowski J., Thompson R.S., Weinandy J.D., Westerink M.A. Pneumococcal polysaccharide vaccination induces polysaccharide-specific B cells in adult peripheral blood expressing $\mathrm{CD} 19^{+} \mathrm{CD} 20^{+} \mathrm{CD} 3{ }^{-} \mathrm{CD} 70{ }^{-} \mathrm{CD} 27^{+} \mathrm{IgM}^{+} \mathrm{CD}^{2} 3^{+} \mathrm{CD}^{+} \%$. Vaccine, 2013, Vol. 31, pp. 4632-4640.

22. Lin Z., Chiang N.Y., Chai N., Seshasayee D., Lee W.P., Balazs M., Nakamura G., Swem L.R. In vivo antigendriven plasmablast enrichment in combination with antigen-specific cell sorting to facilitate the isolation of rare monoclonal antibodies from human B cells. Nat. Protoc., 2014, Vol. 9, no. 7, pp. 1563-1577.

23. Lu D.R., Tan Y.C., Kongpachith S., Cai X., Stein E.A., Lindstrom T.M., Sokolove J., Robinson W.H. Identifying functional anti-Staphylococcus aureus antibodies by sequencing antibody repertoires of patient plasmablasts. Clin. Immunol., 2014, Vol. 152, no. 1-2, pp. 77-89.

24. Mahnke Y.D., Roederer M. Optimizing a multicolor immunophenotyping assay. Clin. Lab. Med., 2007, Vol. 27, pp. 469-485.

25. Meyer J.P., Adumeau P., Lewis J.S., Zeglis B.M. Click chemistry and radiochemistry: the first 10 years. Bioconjug. Chem., 2016, Vol. 27, no. 12, pp. 2791-2807. 
26. Nakamura G., Chai N., Park S., Chiang N., Lin Z., Chiu H., Fong R., Yan D., Kim J., Zhang J., Lee W.P., Estevez A., Coons M., Xu M., Lupardus P., Balazs M., Swem L.R. An in vivo human-plasmablast enrichment technique allows rapid identification of therapeutic influenza A antibodies. Cell Host Microbe, 2013, Vol. 14, no. 1, pp. 93-103.

27. Pallikkuth S., Pilakka Kanthikeel S., Silva S.Y., Fischl M., Pahwa R., Pahwa S. Upregulation of IL-21 receptor on B cells and IL-21 secretion distinguishes novel $2009 \mathrm{H} 1 \mathrm{~N} 1$ vaccine responders from nonresponders among HIVinfected persons on combination antiretroviral therapy. J. Immunol., 2011, Vol. 186, no. 11, pp. 6173-6281.

28. Plotkin S.A. Correlates of protection induced by vaccination. Clin. Vaccine Immunol., 2010, Vol. 17, no. 7, pp. 1055-1065.

29. Robinson W.H. Sequencing the functional antibody repertoire - diagnostic and therapeutic discovery. Nat. Rev. Rheumatol., 2015, Vol. 11, no. 3, pp. 171-182.

30. Roederer M. Spectral compensation for flow cytometry: visualization artifacts, limitations, and caveats. Cytometry, 2001, Vol. 45, no. 3, pp. 194-205.

31. Simons B.C., Spradling P.R., Bruden D.J.T., Zanis C., Case S., Choromanski T.L., Apodaca M., Brogdon H.D., Dwyer G., Snowball M., Negus S., Bruce M.G., Morishima C., Knall C., McMahon B.J. A longitudinal hepatitis B vaccine cohort demonstrates long-lasting hepatitis B virus (HBV) cellular immunity despite loss of antibody against HBV surface antigen. J. Infect., 2016, Vol. 214, no. 2, pp. 273-280.

32. Smith K., Crowe S.R., Garman L., Guthridge C.J., Muther J.J., McKee E., Zheng N.Y., Farris A.D., Guthridge J.M., Wilson P.C., James J.A. Human monoclonal antibodies generated following vaccination with AVA provide neutralization by blocking furin cleavage but not by preventing oligomerization. Vaccine, 2012, Vol. 30, no. 28, pp. 4276-4283.

33. Smith K., Garman L., Wrammert J., Zheng N.Y., Capra J.D., Ahmed R., Wilson P.C. Rapid generation of fully human monoclonal antibodies specific to a vaccinating antigen. Nat. Protoc., 2009, Vol. 4, no. 3, pp. 372-384.

34. Stathopoulos P., Kumar A., Nowak R.J., O’Connor K.C. Autoantibody-producing plasmablasts after B cell depletion identified in muscle-specific kinase myasthenia gravis. JCI Insight, 2017, Vol. 2, no. 17, e94263. doi: 10.1172/jci.insight.94263.

35. Tian C., Chen Y., Liu Y., Wang S., Li Y., Wang G., Xia J., Zhao X. A., Huang R., Lu S., Wu C. Use of ELISpot assay to study HBs-specific B cell responses in vaccinated and HBV infected humans. Emerg. Microbes Infect., 2018, Vol. 7, no. 1, 16. doi: 10.1038/s41426-018-0034-0.

36. Vira S., Mekhedov E., Humphrey G., Blank P.S. Fluorescent-labeled antibodies: balancing functionality and degree of labeling. Anal. Biochem., 2010, Vol. 402, no. 2, pp. 146-150.

37. Wilson P.C., Andrews S.F. Tools to therapeutically harness the human antibody response. Nat. Rev. Immunol., 2012, Vol. 12, no. 10, pp. 709-719.

\section{Авторы:}

Бязрова М.Г. - младший научный сотрудник лаборатории иммунохимии ФГБУ «ГНЦ, Институт иммунологии “» Федерального медико-биологического агентства России; аспирант кафедры иммунологии, ФГБОУ ВО «Московский государственный университет имени М.В. Ломоносова», Москва, Россия

Топтыгина А.П. - д.м.н., профессор, ведущий научный сотрудник лаборатории цитокинов ФБУН «Московский научно-исследовательский институт эпидемиологии и микробиологии имени Г.Н. Габричевского» Роспотребнадзора; профессор кафедры иммунологии, ФГБОУ ВО «Московский государственный университет имени М.В. Ломоносова», Москва, Россия

Митина Т.А. - д.м.н., руководитель отделения клинической гематологии и иммунотерапии ГБУЗ МО «Московский областной научно-исследовательский клинический институт имени М.Ф. Владимирского», Москва, Россия

Филатов А.В. - д.б.н., профессор, заведующий лабораторией иммунохимии ФГБУ «ГНЦ „Институт иммунологии “» Федерального медико-биологического агентства России; профессор кафедры иммунологии, ФГБОУ ВО «Московский государственный университет имени М.В. Ломоносова», Москва, Россия

\section{Authors:}

Byazrova M.G., Junior Research Associate, Laboratory of Immunochemistry, National Research Center "Institute of Immunology”, Federal Medical-Biological Agency of Russia; Postgraduate Student, Lomonosov Moscow State University, Moscow, Russian Federation

Toptygina A.P., PhD, MD (Medicine), Professor, Leading Research Associate, Cytokine Laboratory, G. Gabrichevsky Research Institute for Epidemiology and Microbiology; Professor, Department of Immunology, Lomonosov Moscow State University, Moscow, Russian Federation

Mitina T.A., PhD, MD (Medicine), Head, Department of Clinical Hematology and Immunotherapy, M. Vladimirsky Moscow Regional Research and Clinical Institute, Moscow, Russian Federation

Filatov A. V., PhD, MD (Biology), Professor, Head, Laboratory of Immunoc hemistry, National Research Center "Institute of Immunology”, Federal Medical-Biological Agency of Russia; Professor, Department of Immunology, Lomonosov Moscow State University, Moscow, Russian Federation

Received 01.06.2020

Accepted 16.06.2020 